\title{
POTENSI DAN EKSISTENSI CADANGAN PANGAN MASYARAKAT DI KABUPATEN PATI
}

\section{THE POTENTIALS AND EXISTING OF COMMUNITY FOOD RESERVE IN PATI REGENCY}

\author{
Suroso \\ Badan Perencanaan Pembangunan Daerah Kabupaten Pati \\ Email : surosopati321@gmail.com
}

Naskah Masuk: 11 Oktober 2017 Naskah Revisi: 25 Oktober 2017 Naskah Diterima: 8 November 2017

\begin{abstract}
Food reserve is very important to guarantee the fulfilment of the community's consumption needs. The aim of the research was to analyse the domestic potential, the existing, and the coverage of community food reserve in the study area. This research used quantitative and descriptive approaches. The variables consisted of the potential, the existing, and the coverage of food reserve. Data were collected through interview and survey for the primary data. Meanwhile, the observation on the relevant documents was conducted to obtain the secondary data. Data were analyzed descriptively. The research had 9 findings. Firstly, the average of the domestic potential of the food reserve was 237,030,630.47 $\mathrm{kg}$ annually. Secondly, the existing of the food reserve at the licensed institutions was 4,107,861.28 kg. Thirdly, the potential proxy of the food reserve at the unlicensed institutions was 232,996,149.68 kg. Fourthly, the government food reserve was 14,904,773.4 kg. Fifthly, the total of the monthly community food consumption was 9,330,835.50 kg. Sixthly, the coverage of the potential of food reserve was 25.4 months. Seventhly, the coverage for existing of food reserve at the licensed institutions was 0.44 month (13 days). Eighthly, the coverage of the food reserve at the outside of licensed institutions was 24.96 months. Ninthly, the coverage of the government food reserve was 1.597 months (47.92 days).
\end{abstract}

Keywords: coverage, food, potential, reserve

\begin{abstract}
ABSTRAK
Cadangan pangan sangat penting untuk menjamin pemenuhan kebutuhan konsumsi pangan masyarakat. Tujuan penelitian adalah untuk menganalisis potensi domestik, eksistensi, dan coverage cadangan pangan masyarakat di lokasi penelitian. Penelitian menggunakan pendekatan deskriptif-kuantitatif. Variabel penelitian meliputi potensi, eksistensi, dan coverage cadangan pangan. Pengumpulan data primer dilakukan dengan menggunakan teknik wawancara dan survei. Sedangkan, observasi dokumen yang relevan dilakukan untuk memperoleh data sekunder. Analisis data dilakukan secara diskriptif. Penelitian ini memiliki 9 temuan. Pertama, rata-rata potensi cadangan pangan di area studi sebanyak 237.030.630,47 kg pertahun. Kedua, eksistensi cadangan pangan milik usaha pangan berijin sebanyak 4.107.861,28 kg. Ketiga, proksi potensi cadangan pangan milik masyarakat umum nonusaha pangan berijin sebesar 232.996.149,68 kg. Keempat, cadangan pangan milik pemerintah yang meliputi lumbung pangan daerah dan BULOG sebanyak 14.904.773,4 kg. Kelima, jumlah konsumsi pangan penduduk perbulan sebanyak 9.330.835,50. Keenam, coverage potensi cadangan pangan domestik sebesar 25,40 bulan (2,12 tahun). Ketujuh, coverage eksistensi cadangan pangan masyarakat pada lembaga berijin sebesar 0,44 bulan (13 hari). Kedelapan, coverage potensi cadangan pangan pada masyarakat umum sebesar 24,96 bulan. Kesembilan, coverage cadangan pangan milik pemerintah sebesar 1,597 bulan (47,92 hari).
\end{abstract}

Kata kunci: cakupan, pangan, potensi, cadangan 


\section{PENDAHULUAN}

Pangan merupakan kebutuhan dasar manusia yang paling hakiki bagi setiap orang. Ketidakcukupan pangan berpotensi mengganggu stabilitas sosial. Apabila pangan tersedia sesuai dengan kebutuhan dan terjangkau oleh daya beli masyarakat, maka dukungan terhadap stabilitas nasional di bidang ekonomi dan politik akan terwujud (Witoro dkk, 2006).

Pengembangan cadangan pangan sebagai salah satu aspek penting dalam ketahanan pangan saat ini menjadi sangat mendesak untuk dikembangkan. Bank Dunia dikutip Badan Ketahanan Pangan (2011) menyampaikan bahwa cadangan pangan Indonesia berada di titik terendah sehingga berpotensi menjadi masalah serius jika tidak diatasi sejak awal, mengingat cadangan pangan dunia turun hampir setengahnya. Kondisi rendahnya cadangan pangan diantaranya dipengaruhi: (a) kondisi iklim di Indonesia tidak menentu yang menyebabkan bencana banjir, dan kekeringan sehingga menuntut manajemen cadangan pangan yang efektif dan efisien yang dapat mengatasi kerawanan pangan; (b) masa panen tidak merata antarwaktu dan antardaerah mengharuskan adanya cadangan pangan; dan (c) banyaknya kejadian darurat memerlukan adanya cadangan pangan untuk penanganan pascabencana, penanganan rawan pangan, dan bantuan pangan wilayah. Disamping itu, cadangan pangan juga dapat digunakan untuk mengantisipasi kemungkinan terjadinya kekurangan pangan yang bersifat sementara yang disebabkan gangguan atau terhentinya pasokan pangan, misalnya karena putusnya prasarana dan sarana transportasi akibat bencana alam.
Era otonomi daerah untuk mewujudkan tersebarnya cadangan pangan di semua lini pemerintahan dan komponen masyarakat dengan sasaran terjaminnya pemenuhan kebutuhan konsumsi pangan. Oleh karena itu, struktur/kelembagaan yang diusulkan dalam rangka pengembangan cadangan pangan masyarakat adalah menumbuhkembangkan dan memelihara tradisi masyarakat secara perorangan dengan menyisihkan sebagian hasil panen untuk cadangan pangan, dan (2) menumbuhkembangkan tradisi masyarakat melakukan cadangan pangan secara kolektif dengan membangun lumbung pangan (Rachman dkk, 2005).

Cadangan pangan sangat penting dalam menjamin ketersediaan pangan masyarakat. Penelitian ini memiliki tujuan: (1) menganalisis potensi domestik cadangan pangan masyarakat; (2) menganalisis eksistensi cadangan pangan masyarakat; dan (3) menganalisis coverage cadangan pangan masyarakat.

\section{TINJAUAN PUSTAKA}

\section{Pangan dan Ketersediaan Pangan}

Pangan menurut UU No. 18 Tahun 2012 adalah segala sesuatu yang berasal dari sumber hayati dan air, baik yang diolah maupun tidak diolah yang diperuntukan sebagai makanan atau minuman bagi konsumsi manusia, termasuk bahan tambahan pangan, bahan baku pangan, dan bahan lain yang digunakan dalam proses penyiapan, pengolahan, dan/atau pembuatan makanan atau minuman. Ketersediaan pangan dapat diusahakan dari hasil produksi pangan, perdagangan pangan atau peredaran pangan.

Menurut ASEAN Food Security Information and Training Center dalam Hanani (2009), untuk mencapai 
ketahanan pangan yang mantap maka rasio cadangan pangan terhadap kebutuhan domestik (Food Security Ratio) setidaknya 20\%. Jika ukuran tersebut yang dipakai dan ketergantungan yang sangat tinggi terhadap beras tak berubah, maka tantangan untuk mencapai status ketahanan pangan yang mantap sangat sulit karena food security ratio beras di Indonesia baru mencapai 4,38\%.

\section{Kewajiban Negara dan Hak Atas Pangan}

Hak Atas Pangan diatur dalam Undang-Undang No. 11 Tahun 2005 tentang Kovenan Internasional tentang Hak-hak Ekonomi Sosial dan Budaya (International Covenant on Economic, Social, and Cultural Rights). Komite Hak Ekonomi Sosial dan Budaya PBB dalam Komentar Umum (General Comment) No. 12 Tahun 1999 menyatakan bahwa Hak atas Pangan yang layak dapat terwujud jika setiap laki-laki, perempuan dan anak-anak, baik secara sendiri maupun dalam komunitas memiliki akses fisik dan ekonomi setiap saat ke pangan yang layak atau sarana-sarana untuk pembeliannya. Hak atas Pangan yang layak dapat diwujudkan secara bertahap. Hak atas Pangan yang layak mengandung: (a) Tersedianya pangan dalam jumlah dan kualitas yang mencukupi untuk memenuhi kebutuhan, bebas dari bahan berbahaya, dan dapat diterima oleh budaya masyarakat; dan b) aksesibilitas dari pangan yang berkelanjutan dan tidak mencampuri penikmatan hak asasi manusia yang lain.

Terkait kewajiban negara atas pangan, Undang-Undang No. 11 Tahun 2005 Pasal 11 menyebutkan: (1) Negara pihak dalam kovenan mengakui bahwa setiap orang memiliki hak atas standar hidup yang layak untuk dirinya dan keluarganya, termasuk kelayakan pangan, sandang dan perumahan, dan untuk melanjutkan peningkatan kondisi kehidupannya. Negara mengambil langkah-langkah yang tepat untuk memastikan kerja sama internasional berdasarkan kebebasan dalam memberikan persetujuan; dan (2) Negara pihak dalam kovenan mengakui hak dasar setiap orang untuk bebas dari kelaparan, akan mengambil langkah secara sendiri atau melalui kerjasama internasional.

\section{Konsep Pengelolaan Cadangan Pangan}

Cadangan pangan merupakan aspek penting dalam sistem pangan. Pangan yang cukup jumlahnya harus tersedia dan mudah diakses oleh setiap orang sehingga kebutuhan pangan terjamin pemenuhannya sepanjang waktu. Belajar dari pengalaman tentang pentingnya ketersediaan pangan sepanjang musim, sejak lama masyarakat desa di berbagai pelosok Indonesia mengembangkan cadangan pangan berupa lumbung. Lumbung desa yang dikelola secara bersama-sama mempunyai peran sosial dalam menumbuhkan solidaritas dan kerjasama warga untuk memenuhi kebutuhan pangan (Witoro, dkk., 2006).

Lumbung pangan masyarakat sebagai salah satu lembaga tunda jual merupakan lembaga penunjang ketahanan pangan lokal. Fungsi utamanya adalah sebagai penunjang cadangan pangan kolektif yang sementara ini lebih bersifat sosial. Melalui diversifikasi kegiatan lumbung pangan juga memberikan peluang peningkatan penghasilan bagi anggotanya. Dengan berkembangnya sistem distribusi dan perdagangan saat 
ini, lembaga tersebut mempunyai potensi untuk berkembang menjadi lembaga ekonomi perdesaan yang bergerak baik kegiatan produksi pangan dari hulu hingga hilir (Irham, 2006).

Organisasi ekonomi perdesaan harus dipandang sebagai bagian dari sistem masyarakat perdesaan yang perlu mendapat perhatian serius karena hingga kini aspek organisasi ekonomi tersebut masih menjadi titik lemah dalam memasuki era pasar bebas. Suatu lembaga atau organisasi lokal yang dinilai bisa mendorong kemajuan masyarakat harus mampu menjaring partisipasi masyarakat secara masif (Pranadji, 2003).

Partisipasi dan pemberdayaan petani melalui organisasi formal merupakan hal yang sangat penting di Indonesia. Namun demikian, keberhasilannya sangat terbatas. Negara menginginkan petani diorganisasikan secara formal, sementara pasar cenderung menghendaki petani (secara individu dan kelompok) untuk berperilaku efisien dan menguntungkan. Melalui pendekatan paham kelembagaan baru, petani dapat terdorong mengorganisasi dirinya. Pendekatan tersebut mampu mengatasi berbagai kekurangan pendekatan sebelumnya. Berdasarkan pendekatan paham kelembagaan baru, pengembangan keorganisasian petani perlu memperhatikan prinsip-prinsip bahwa organisasi formal adalah sebuah opsi, mengutamakan fungsi daripada administrasi birokrasi, organisasi sebagai alat, penghargaan pada rasionalitas petani, dan perlunya penguatan relasirelasi vertikal petani (Syahyuti, 2010).

Salah satu aspek penting dalam membangun ketahanan pangan adalah ketersediaan pangan dalam jumlah dan jenis yang cukup serta adanya sistem kelembagaan di masyarakat dalam pengelolaan pangan. Ketersediaan pangan dibangun melalui peningkatan kemampuan produksi di dalam negeri, peningkatan pengelolaan cadangan pangan, serta distribusi pangan untuk mengisi kesenjangan antardaerah dalam aspek produksi dan kebutuhan. Cadangan pangan dapat dilakukan oleh pemerintah (Perum BULOG) dan masyarakat (termasuk swasta). Cadangan pangan yang dikelola oleh masyarakat/rumah tangga sangat penting dalam menjaga ketahanan pangan/mengatasi kerawanan pangan di tingkat rumah tangga. Pengembangan sistem cadangan pangan masyarakat baik di tingkat rumah tangga, kelompok, wilayah perdesaan di daerah dinilai strategis dalam rangka mengurangi risiko kerawanan pangan pada situasi yang tidak normal (Rachmat, dkk,. 2010).

\section{METODE PENELITIAN}

Penelitian ini menggunakan pendekatan kuantitatif-deskriptif. Lokasi studi di Kabupaten Pati. Penelitian ini memiliki tiga variabel penelitian, yaitu (1) potensi cadangan pangan; (2) eksistensi cadangan pangan; dan (3) coverage cadangan pangan. Data penelitian meliputi data primer dan data sekunder. Pengumpulan data primer dilakukan melalui wawancara dan survey, sementara pengumpulan data sekunder dilakukan menggunakan observasi dokumen institusi terkait. Penelitian ini menggunakan analisis deskriptif, sedangkan analisis cadangan pangan masyarakat menggunakan rumus berikut:

1) Produksi Padi Neto (Deptan, 2007)

$$
P_{\text {net }}=P(1-(s+f+w)
$$


$\mathrm{P}_{\text {net }}=$ produksi neto padi

$\mathrm{C}=$ faktor konversi beras $(0,632)$

$\mathrm{P}=$ produksi padi perkawasan (kecamatan)

$\mathrm{s} \quad=$ nilai konversi bibit $(0,0088)$

$\mathrm{f}=$ nilai konversi pakan $(0,02)$

$\mathrm{W}=$ nilai konversi tercecer $(0,054)$

2) Produksi Beras (Deptan, 2007)

$\mathrm{R}_{\text {net }}=\mathrm{P}_{\text {net }} \times \mathrm{C}$

$\mathrm{R}_{\text {net }}=$ produksi neto beras

$\mathrm{P}_{\text {net }}=$ produksi neto padi

$\mathrm{C}=$ faktor konversi beras $(0,632)$

3) Konsumsi Beras (BPS, 2015)

$\mathrm{Kk}_{\mathrm{r}}=\mathrm{Pi} \times \mathrm{K}_{\mathrm{nr}}$

$\mathrm{Kk}_{\mathrm{r}}=$ konsumsi komulatif beras

$\mathrm{Pi}=$ jumlah penduduk kawasan $\mathrm{i}$

$\mathrm{K}_{\mathrm{nr}}=$ konsumsi normatif beras perkapita

4) Potensi Cadangan Pangan

$\mathrm{PCP}=\mathrm{R}_{\mathrm{net}}-\mathrm{Kk}_{\mathrm{r}}$

$\mathrm{PCP}=$ potensi cadangan pangan

$\mathrm{R}_{\text {net }}=$ produksi neto beras

$\mathrm{Kk}_{\mathrm{r}}=$ konsumsi komulatif beras

\section{HASIL DAN PEMBAHASAN}

\section{Standar Normatif Konsumsi Pangan Masyarakat}

Hasil survei BPS (2015 dan 2016) menunjukkan bahwa konsumsi perkapita beras perminggu: (1) Tahun 2007 sebanyak 1,740 kg; (2) Tahun 2008 sebanyak 1,797 kg; (3) Tahun 2009 sebanyak 1,755 kg; (4) Tahun 2010 sebanyak 1,733 kg; (5) Tahun 2011 sebanyak 1,721 kg; (6) tahun 2012 sebanyak 1,675 kg; (7) tahun 2013 sebanyak 1,642 kg; (8) Tahun 2014 sebanyak 1,626 kg; dan (9) Tahun 2015 sebanyak $1,628 \mathrm{~kg}$. Ini berarti rata-rata konsumsi perkapita beras perminggu sebanyak $1,702 \mathrm{~kg}$.

Bila satu minggu sama dengan 7 hari dan 1 bulan sama dengan 30 hari maka rata-rata konsumsi perkapita beras perbulan sebesar $7,29 \mathrm{~kg}$ dan rerata konsumsi pangan perkapita pertahun (365 hari) sebesar 88,741 kg. Standar normatif konsumsi pangan (beras) ditunjukkan Tabel 1.

Tabel 1.

Standar Normatif Konsumsi Beras Perkapita

\begin{tabular}{ccccc}
\hline \multirow{2}{*}{ No } & \multirow{2}{*}{ Tahun } & \multicolumn{3}{c}{ Konsumsi Pangan Perkapita Beras (kg) } \\
\cline { 3 - 5 } & & Perminggu (7 hr) & Perbulan (30 hr) & Pertahun (1 th = 365 hr) \\
\hline 1 & 2007 & 1,740 & 7,46 & 90,729 \\
2 & 2008 & 1,797 & 7,70 & 93,701 \\
3 & 2009 & 1,755 & 7,52 & 91,511 \\
4 & 2010 & 1,733 & 7,43 & 90,364 \\
5 & 2011 & 1,721 & 7,38 & 89,738 \\
6 & 2012 & 1,675 & 7,18 & 87,339 \\
7 & 2013 & 1,642 & 7,04 & 85,619 \\
8 & 2014 & 1,626 & 6,97 & 84,784 \\
9 & 2015 & 1,628 & 6,98 & 84,889 \\
\hline \multicolumn{2}{c}{ Rata-rata } & $\mathbf{1 , 7 0 2}$ & $\mathbf{7 , 2 9}$ & $\mathbf{8 8 , 7 4 1}$ \\
\hline \multicolumn{2}{c}{ Suny }
\end{tabular}

Sumber : BPS Kab. Pati, 2015 dan 2016 


\section{Potensi Cadangan Pangan}

Tahun 2014 Kabupaten Pati memiliki luas panen seluas 92.559 ha yang menghasil produksi sebanyak 497.081 ton. Produksi bersih padi $\left(\mathrm{P}_{\text {net }}\right)$ adalah produksi bruto dikurangi kebutuhan bibit (s) dengan nilai konversi $0,0088(0,88 \%)$, dikurangi keperluan pakan (f) dengan nilai konversi 0,02 (2\%) dan produksi padi tercecer (w) dengan nilai 0,054 setara 5,4\%, maka produksi netto padi (gabah) sebanyak 455.923 ton. Produksi neto padi sebesar 455.922,69 ton dan nilai konversi gabah menjadi beras 0,632 maka produksi beras neto $\left(\mathrm{R}_{\text {net }}\right)$ sebesar $288.143,14$ ton atau $288.143 .142 \mathrm{~kg}$. Konsumsi perkapita beras perminggu sebanyak $1,702 \mathrm{~kg}$. Bila satu minggu (7 hari) dan satu tahun 365 hari maka rata-rata konsumsi perkapita beras pertahun sebesar $88,741 \mathrm{~kg}$. Jumlah penduduk sebanyak 1.261.531 orang dan konsumsi perkapita pertahun sebanyak $88,741 \mathrm{~kg}$, maka komulatif konsumsi beras selama setahun sebanyak 111.949.963,01 kg (111.950 ton). Hal tersebut berarti potensi cadangan pangan sebanyak 176.193.179,10 kg yang berasal dari produksi beras neto sebanyak $288.143 .142 \mathrm{~kg}$ dikurangi konsumsi beras penduduk sebanyak $111.949 .963,01 \mathrm{~kg}$.

Kabupaten Pati di Tahun 2015 memiliki luas panen sebanyak 109.486 ha yang menghasil produksi sebanyak 646.068 ton. Produksi bersih padi $\left(\mathrm{P}_{\text {net }}\right)$ adalah produksi bruto dikurangi kebutuhan bibit (s), dikurangi keperluan pakan (f) dan produksi padi tercecer (w), maka produksi neto padi (gabah) sebanyak 592.574 ton. Bila produksi neto padi sebesar 592.574 ton, maka produksi beras neto sebesar 374.506,5 ton yang berasal dari produksi neto padi dikalikan nilai konversi 0,632 yang setara dengan (63,2\%). Jumlah penduduk Tahun 2015 sebanyak 1.265.286 orang. Bila konsumsi perkapita pertahun sebanyak $88,741 \mathrm{~kg}$, maka komulatif konsumsi beras selama setahun sebanyak 112.283.186,77 kg. Produksi beras neto sebanyak 374.506.496 kg dan konsumsi beras penduduk sebanyak 112.283.186,77 kg maka potensi cadangan pangan sebanyak 262.223.309,22 kg.

Tahun 2016 Kabupaten Pati memiliki luas panen sebanyak 114.401,6 ha yang menghasil produksi sebanyak 666.344 ton. Produksi bersih padi $\left(\mathrm{P}_{\text {net }}\right)$ adalah produksi bruto dikurangi kebutuhan bibit (s), dikurangi keperluan pakan (f) dan produksi padi tercecer (w), maka produksi neto padi (gabah) sebanyak 611.171 ton. Bila produksi neto padi sebesar 611.171 ton, maka produksi beras neto sebesar 386.260 ton yang berasal dari jumlah gabah kali nilai konversi 0.632 yang setara dengan $(63,2 \%)$. Tahun 2016, jumlah penduduk sebanyak 1.279.950 orang. Standar konsumsi perkapita pertahun sebanyak $88,741 \mathrm{~kg}$ maka konsumsi beras selama setahun sebanyak $113.584 .489,92 \mathrm{~kg}$. Hal tersebut berarti di tahun 2016, Kabupaten Pati memiliki potensi cadangan pangan sebanyak 272.675.403,10 kg yang berasal dari produksi beras neto sebanyak $386.259 .893 \mathrm{~kg}$ dikurangi nilai konsumsi beras penduduk sebanyak $113.584 .489,92 \mathrm{~kg}$. Produksi pangan padi dapat disimpan dalam waktu relatif lama maka penghitungan cadangan pangan masyarakat dapat menggunakan rata-rata cadangan pangan beberapa tahun yang ditunjukkan Tabel 2. 
Tabel 2.

Potensi Rata-rata Cadangan Pangan Masyarakat di Kabupaten Pati

\begin{tabular}{llrrrrr}
\hline \multirow{2}{*}{ No } & \multirow{2}{*}{ Kecamatan } & \multicolumn{3}{c}{ Cadangan Pangan Beras (ton) } & \multicolumn{2}{c}{$\begin{array}{c}\text { Rata-rata Cadangan } \\
\text { Pangan }\end{array}$} \\
\cline { 3 - 7 } & & \multicolumn{1}{c}{ Th 2014 } & \multicolumn{1}{c}{ Th 2015 } & \multicolumn{1}{c}{ Th 2016 } & \multicolumn{1}{c}{ (ton) } & \multicolumn{1}{c}{ (kg) } \\
\hline 1 & Sukolilo & $29.100,12$ & $53.452,16$ & $44.396,48$ & $42.316,25$ & $42.316 .254,21$ \\
2 & Kayen & $21.926,35$ & $32.317,30$ & $30.594,94$ & $28.279,53$ & $28.279 .532,07$ \\
3 & Tambakromo & $20.385,63$ & $19.901,49$ & $20.853,78$ & $20.380,30$ & $20.380 .299,61$ \\
4 & Winong & $19.222,40$ & $21.186,82$ & $24.285,47$ & $21.564,89$ & $21.564 .894,35$ \\
5 & Pucakwangi & $15.240,72$ & $17.045,57$ & $16.898,60$ & $16.394,96$ & $16.394 .960,91$ \\
6 & Jaken & $13.341,30$ & $14.862,89$ & $14.916,97$ & $14.373,72$ & $14.373 .718,69$ \\
7 & Batangan & 214,88 & $2.706,16$ & $2.524,93$ & $1.815,32$ & $1.815 .321,90$ \\
8 & Juwana & $(4.943,03)$ & $(380,28)$ & 64,52 & $(1.752,93)$ & $(1.752 .930,32)$ \\
9 & Jakenan & $14.270,14$ & $21.626,12$ & $23.211,44$ & $19.702,57$ & $19.702 .567,58$ \\
10 & Pati & $2.482,79$ & $8.487,08$ & $14.041,84$ & $8.337,24$ & $8.337 .235,84$ \\
11 & Gabus & $14.911,95$ & $24.275,10$ & $24.422,79$ & $21.203,28$ & $21.203 .281,33$ \\
12 & Margorejo & $6.385,81$ & $9.129,65$ & $10.489,57$ & $8.668,34$ & $8.668 .340,83$ \\
13 & Gembong & $(892,16)$ & $(110,73)$ & $(79,17)$ & $(360,68)$ & $(360.684,27)$ \\
14 & Tlogowungu & $2.018,63$ & $2.139,82$ & $3.743,37$ & $2.633,94$ & $2.633 .938,73$ \\
15 & Wedarijaksa & $(2.828,34)$ & $(2.863,52)$ & $(885,57)$ & $(2.192,48)$ & $(2.192 .477,68)$ \\
16 & Trangkil & 688,39 & $1.232,26$ & $1.918,20$ & $1.279,62$ & $1.279 .619,47$ \\
17 & Margoyoso & $1.650,69$ & $5.118,75$ & $4.909,93$ & $3.893,12$ & $3.893 .123,21$ \\
18 & Gngwungkal & $5.005,26$ & $6.778,88$ & $7.772,21$ & $6.518,78$ & $6.518 .783,21$ \\
19 & Cluwak & $5.290,18$ & $6.974,46$ & $7.488,49$ & $6.584,38$ & $6.584 .379,14$ \\
20 & Tayu & $6.167,67$ & $11.079,68$ & $8.847,28$ & $8.698,21$ & $8.698 .211,42$ \\
21 & Dukuhseti & $6.553,81$ & $7.263,64$ & $12.259,33$ & $8.692,26$ & $8.692 .260,24$ \\
\hline & Kab Pati & $176.193,18$ & $262.223,31$ & $272.675,40$ & $237.030,63$ & $237.030 .630,47$ \\
\hline
\end{tabular}

Sumber : Dinas Ketahanan Pangan, 2017

\section{Eksistensi Cadangan Pangan Milik Masyarakat}

Berdasarkan Permendagri No. 30 Tahun 2008, cadangan pangan nasional terdiri dari cadangan pangan pemerintah dan cadangan pangan masyarakat. Eksistensi cadangan pangan masyarakat dalam studi ini terbatas pada cadangan pangan pada lembaga formal usaha pangan yang mencakup: (1) cadangan pangan lumbung pangan masyarakat; (2) cadangan pangan penggilingan padi; dan (3) cadangan pangan pebisnis (distributor, grosir dan supplier). Eksistensi cadangan pangan komposit milik masyarakat ditunjukkan pada Tabel 3.

Pertama, eksistensi cadangan pangan masyarakat yang tersimpan di 37 lumbung pangan masyarakat sebanyak $37.768 \mathrm{~kg}$ gabah setara dengan beras $23.869 \mathrm{~kg}$. Kedua, eksistensi cadangan pangan milik masyarakat pebisnis (supplier, grosir dan distributor). Komulatif cadangan pangan yang dimiliki oleh 21 supplier sebanyak $770.526,75 \mathrm{~kg}$ beras. Distributor dan grosir yang memiliki stok pangan hanya dua buah dengan kepemilikan cadangan pangan sebanyak $2.264 \mathrm{~kg}$ beras. Komulatif cadangan pangan yang dimiliki pebisnis sebanyak $772.790,75 \mathrm{~kg}$ beras. Ketiga, eksistensi cadangan pangan masyarakat yang berada di penggilingan padi. Kabupaten Pati memiliki 856 penggilingan padi dan tiap penggilingan padi memiliki rata-rata cadangan pangan $3.868,23 \mathrm{~kg}$, maka 
produksi cadangan pangan sebanyak 3.311.201,53 kg. Eksistensi cadangan pangan komposit milik masyarakat $4.107 .861,28 \mathrm{~kg}$.

Tabel 3.

Eksistensi Cadangan Pangan Komposit Milik Masyarakat

\begin{tabular}{lcccc}
\hline Kecamatan & $\begin{array}{c}\text { Stok Beras } \\
\text { Milik } \\
\text { Lumbung } \\
\text { pangan } \mathbf{( k g )}\end{array}$ & $\begin{array}{c}\text { Stok Beras } \\
\text { Milik } \\
\text { Pebisnis } \\
\mathbf{( k g )}\end{array}$ & $\begin{array}{c}\text { Cadangan } \\
\text { Pangan Milik } \\
\text { Penggilingan } \\
\text { Padi (kg) }\end{array}$ & $\begin{array}{c}\text { Total } \\
\text { cadangan } \\
\text { Pangan Milik } \\
\text { Masyarakat } \\
\text { (kg) }\end{array}$ \\
\hline Sukolilo & 2.168 & $110.075,25$ & $336.535,67$ & $448.778,92$ \\
Kayen & 1.466 & $110.075,25$ & $259.171,15$ & $370.712,40$ \\
Tambakromo & 1.283 & 0,00 & $154.729,04$ & $156.012,04$ \\
Winong & 2.528 & 0,00 & $278.512,28$ & $281.040,28$ \\
Pucakwangi & 5.005 & 0,00 & $340.403,90$ & $345.408,90$ \\
Jaken & 1.067 & 0,00 & $205.015,98$ & $206.082,98$ \\
Batangan & 506 & $36.691,75$ & $146.992,59$ & $184.190,34$ \\
Juwana & 506 & $73.383,50$ & $81.232,75$ & $155.122,25$ \\
Jakenan & 2.370 & $148.031,00$ & $390.690,83$ & $541.091,83$ \\
Pati & 506 & $110.075,25$ & $131.519,69$ & $242.100,94$ \\
Gabus & 1.011 & $1.000,00$ & $189.543,08$ & $191.554,08$ \\
Margorejo & 1.011 & $73.383,50$ & $119.915,01$ & $194.309,51$ \\
Gembong & 506 & 0,00 & $61.891,62$ & $62.397,62$ \\
Tlogowungu & 1.011 & 0,00 & $100.573,88$ & $101.584,88$ \\
Wedarijaksa & 0 & 0,00 & $46.418,71$ & $46.418,71$ \\
Trangkil & 506 & 0,00 & $38.682,26$ & $39.188,26$ \\
Margoyoso & 506 & 0,00 & $50.286,94$ & $50.792,94$ \\
Gunungwungkal & 506 & 0,00 & $77.364,52$ & $77.870,52$ \\
Cluwak & 506 & 0,00 & $100.573,88$ & $101.079,88$ \\
Tayu & 398 & $110.075,25$ & $73.496,30$ & $183.969,55$ \\
Dukuhseti & 506 & 0,00 & $127.651,46$ & $128.157,46$ \\
\hline Jumlah & 23.869 & $772.790,75$ & $3.311 .201,53$ & $4.107 .861,28$ \\
\hline Sumbr: Dinas Ketan & & &
\end{tabular}

Sumber : Dinas Ketahanan Pangan, 2017

\section{Eksistensi Cadangan Pangan Milik Pemerintah}

Eksistensi cadangan pangan pemerintah dalam studi ini terbatas pada cadangan pangan yang dimiliki gudang pangan pemerintah daerah dan BULOG. Cadangan pangan milik pemerintah daerah dikelola oleh Dinas Ketahanan Pangan. Tahun 2017, gudang pangan milik pemerintah daerah memiliki cadangan pangan berwujud beras sebanyak $5.160 \mathrm{~kg}$ dan gabah sebanyak $8.700 \mathrm{~kg}$. Bila nilai konversi gabah menjadi beras setara dengan 0,632 maka cadangan pangan berwujud gabah setara dengan 5498,4 kg beras. Secara komulatif cadangan pangan milik pemerintah daerah yang dikelola Dinas Ketahanan Pangan adalah 10.658 kg beras (10,66 ton). Selanjutnya cadangan pangan milik BULOG di Kabupaten Pati memiliki cadangan pangan berwujud beras sebanyak $14.894 .115 \mathrm{~kg}(14.894,12$ ton). Eksistensi cadangan pangan milik pemerintah daerah dan BULOG ditunjukkan Tabel 4. 
Tabel 4.

Eksistensi Cadangan Pangan Milik Pemerintah Daerah dan BULOG

\begin{tabular}{llrrr}
\hline No & Cadangan Pangan & $\begin{array}{c}\text { Gudang Pangan } \\
\text { Daerah }\end{array}$ & Bulog & Jumlah \\
\hline 1 & Stok Beras & 5.160 & 14.894 .115 & 14.899 .275 \\
2 & Stok Gabah & 8.700 & 0 & \\
3 & Nilai konversi & 0,632 & 0,632 & \\
4 & Cadangan Pangan Neto & 5498,4 & 0 & 5498,4 \\
\hline \multicolumn{4}{l}{ Total Cadangan Pangan Pemerintah Daerah dan BULOG } & $14.904 .773,4$ \\
\hline
\end{tabular}

Sumber : Pengolahan Data, 2017

\section{Coverage Cadangan Pangan Masyarakat}

Coverage cadangan pangan adalah Coverage cadangan pangan adalah kemampuan cadangan pangan dalam mencukupi kebutuhan pangan untuk rentang waktu tertentu. Bagian sebelumnya telah disebutkan: (1) potensi cadangan pangan diarea studi; (2) eksistensi cadangan pangan masyarakat pada usaha formal yang meliputi: penggilingan padi, usaha dagang dan lumbung masyarakat; dan (3) eksistensi cadangan pangan milik pemerintah. Ini berarti secara implisit, ada cadangan pangan yang dimiliki masyarakat umum nonusaha pangan.

Pertama, coverage rata-rata cadangan pangan domestik sebesar 237.030.630,47 kg pertahun. Dengan jumlah penduduk adalah 1.279.950 orang dan standar konsumsi perkapita perbulan adalah 7,29 kg maka konsumsi beras dari penduduk perbulan adalah 9.330.835,50 $\mathrm{kg}$. Apabila potensi cadangan pangan pertahun 237.030.630,47 $\mathrm{kg}$ dan konsumsi pangan perbulan sebanyak 9.330.835,50 maka coverage potensi cadangan pangan mampu mencukupi kebutuhan pangan penduduk domestik selama 25,40 bulan (2,12 tahun).

Kedua, coverage eksistensi cadangan pangan masyarakat pada usaha formal pangan. Eksistensi cadangan pangan komposit milik masyarakat sebanyak 4.034.480,79 kg. Sementara itu, komulatif konsumsi pangan masyarakat perbulan sebanyak $9.330 .835,50 \mathrm{~kg}$. Hal tersebut berarti coverage eksistensi cadangan pangan masyarakat sebesar 0,44 bulan atau 13 hari.

Ketiga, proksi coverage cadangan pangan milik masyarakat umum nonusaha pangan. Reata-rata potensi cadangan pangan domestik di Kabupaten Pati adalah 237.030.630,47 kg (237.030,63 ton) pertahun. Eksistensi cadangan pangan yang sudah teridentifikasi pada lumbung masyarakat, pebisnis (distributor, grosir dan supplier) dan penggilingan padi sebanyak 4.107.861,28 kg, sehingga proksi potensi cadangan pangan pada masyarakat umum yang belum teridentifikasi sebesar 232.922.769,19 kg. Potensi cadangan pangan (beras) yang dimiliki masyarakat umum yang belum teridentifikasi memiliki proksi sebesar 232.922.769,19 $\mathrm{kg}$ dan apabila konsumsi pangan penduduk perbulan 9.330.835,50 kg maka coverage potensi cadangan pangan pada masyarakat umum yang belum teridentifikasi sebesar 24,96 bulan.

Keempat, coverage cadangan pangan milik pemerintah. Cadangan 
pangan pemerintah yaitu gudang pangan pemerintah daerah dan BULOG. Gudang pangan milik pemerintah daerah memiliki beras dan gabah yang secara komulatif setara dengan $10.658 \mathrm{~kg}$ beras. Sementara itu, cadangan pangan milik BULOG Kabupaten Pati hingga Bulan September 2017 berwujud beras sebanyak $14.894 .115 \mathrm{~kg}(14.894,12$ ton).
Oleh karena itu, komulatif cadangan pangan yang dikelola pemerintah sebesar $14.904 .773,4 \mathrm{~kg}$ dan apabila konsumsi pangan penduduk perbulan sebesar 9.330.835,50 $\mathrm{kg}$ maka coverage cadangan pangan yang dikelola pemerintah adalah 1,597 bulan (47,92 hari). Kondisi coverage cadangan pangan ditunjukkan Gambar 1.

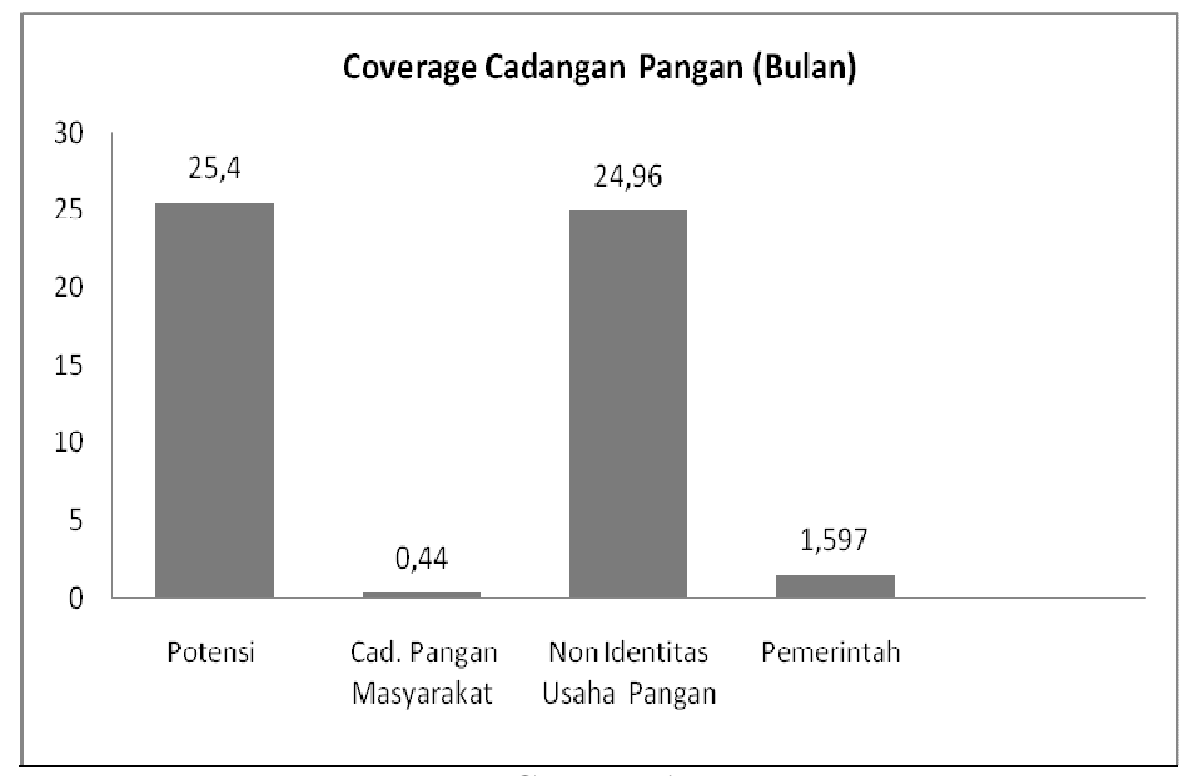

\section{Gambar 1.}

Coverage Cadangan Pangan

Sumber : Pengolahan Data (2017

\section{KESIMPULAN DAN SARAN}

\section{Kesimpulan}

Penelitian ini memiliki 9 temuan. Pertama, rata-rata potensi cadangan pangan di area studi sebanyak $237.030 .630,47 \mathrm{~kg}$ per tahun. Kedua, eksistensi cadangan pangan milik usaha pangan berijin sebanyak 4.107.861,28 kg. Ketiga, produksi potensi cadangan pangan milik masyarakat umum non usaha pangan berijin sebesar 232.996.149,68 kg. Keempat, cadangan pangan milik pemerintah yang meliputi lumbung pangan daerah dan BULOG sebesar 14.904.773,4 kg. Kelima, jumlah konsumsi pangan penduduk perbulan sebanyak 9.330.835,50. Keenam, coverage potensi cadangan pangan domestik sebesar 25,40 bulan (2,12 tahun). Ketujuh, coverage eksistensi cadangan pangan masyarakat pada lembaga berijin sebesar 0,44 bulan atau 13 hari. Kedelapan, coverage potensi cadangan pangan pada masyarakat umum sebesar 24,96 bulan. Kesembilan, coverage cadangan pangan milik pemerintah sebesar 1,6 bulan (47,9 hari). 


\section{Saran}

Berdasarkan hasil penelitian terdapat dua rekomendasi untuk kebijakan ketahanan pangan di Kabupaten Pati. Pertama, Kabupaten Pati memiliki potensi cadangan pangan domestik relatif baik tetapi ada sebagian kawasan yang memiliki tingkat konsumsi pangan lebih besar dari produksi pangan maka guna mendukung akses pangan, kebijakan makro daerah dalam peningkatan cadangan pangan agar diarahkan pada pembangunan lumbung atau gudang pangan daerah yang dekat dengan kawasan potensi cadangan pangan minus dengan pertimbangan pola distribusi untuk mengeliminasi resiko kerawanan pangan ketika ada bencana banjir. Kedua, usaha potensial penyimpanan cadangan pangan mencakup lumbung pangan masyarakat, penggilingan padi, distributor, grosir dan supplier tersebar tidak merata. Oleh karena itu, kebijakan cadangan mikro agar diarahkan pada pembangunan lumbung pangan masyarakat dengan memprioritaskan desa-desa yang belum punya usaha tersebut.

\section{DAFTAR PUSTAKA}

Badan Ketahanan Pangan. (2011). Pedoman Teknis Pengembangan Cadangan PanganMasyarakat. Jakarta : Badan Ketahanan Pangan, Kementerian Pertanian.

Badan Pusat Statistik. (2015). Statistik Makro Sektor Pertanian. Jakarta : Pusat Data dan Sistem Informasi Pertanian, Kementerian Pertanian.

Badan Pusat Statistik. (2016). Statistik Makro Sektor Pertanian. Jakarta :
Pusat Data dan Sistem Informasi Pertanian, Kementerian Pertanian.

Departemen Pertanian. (2007). Peta Akses Pangan Pedesaan. Jakarta : Badan Ketahanan Pangan.

Dinas Ketahanan Pangan. (2017). Penghitungan Cadangan Pangan Masyarakat di Kabupaten Pati. Pati: Dinas Ketahanan Pangan.

Hanani, N. (2009). Sumbangan Pemikiran Arah Pembangunan Ketahanan Pangan. Round-Table Discussion "Strategi Ketahanan Pangan dan Pengentasan Kemiskinan Petani" 23 Juni 2009. Surabaya.

Irham. (2006). Peran Lumbung Pangan dalam Menunjang Ketahanan Pangan. Tesis. Yogyakarta : Jurusan Sosial Ekonomi Pertanian Fakultas Pertanian, UGM.

Peraturan Menteri Dalam Negeri Nomor 30 Tahun 2008 tentang Cadangan Pangan Pemerintah Desa.

Pranadji, T. (2003). Reformasi Kelembagaan dan Kemandirian Perekonomian Pedesaan, Kajian pada Kasus Agribisnis Padi Sawah. Seminar Nasional Peluang Indonesia untuk Mencukupi Sendiri Kebutuhan Beras Nasional. Bogor : Badan Litbang Pertanian, Departemen Pertanian.

Rachman, H. P. S., Purwoto, A., Hardono, G . S. (2005). Kebijakan Pengelolaan Cadangan Pangan pada Era Otonomi Daerah dan Perum Bulog. Forum Penelitian Agro Ekonomi, 23(2), 73-83. 
Rachmat, M., Rachman, B., Kustiari, R., Supriyati., Budi, G. S., Wahyuning., Hidayat, D. (2010). Kajian Sistem Kelembagaan Cadangan Pangan MasyarakatPerdesaan untuk Mengurangi 25\% Resiko Kerawanan Pangan. Bogor : Pusat Analisis Sosial Ekonomi dan Kebijakan Pertanian, Kementerian Pertanian.

Syahyuti. (2010). Lembaga dan Organisasi Petani dalam Pengaruh Negara dan Pasar. Forum Penelitian Agro Ekonomi, 28(1), 35-53.

United Nations. (1999). General Comment No. 12 tahun 1999. New York : Komite Hak Ekonomi Sosial dan Budaya PBB.
Undang-Undang Nomor 11 Tahun 2005 tentang Kovenan Internasional tentang Hak-hak Ekonomi Sosial dan Budaya.

Undang-Undang Nomor 18 Tahun 2012 tentang Pangan.

Witoro, Y., Napiri., Sihaloho, M. (2006). Lumbung Pangan : Jalan Menuju Keterjaminan Pangan. Laporan Tahunan. Bogor : Koalisi Rakyat untuk Kedaulatan Pangan (KRKP), Sindang barang.

\section{BIODATA PENULIS}

Suroso, lahir 19 Maret 1966 di Kabupaten Pati Jawa Tengah. Magister Perencanaan Kota dan Daerah Universitas Gajah Mada. Bekerja di Badan Perencanaan Pembangunan Daerah Kabupaten Pati. 